\title{
BMJ Open Does remote patient monitoring reduce acute care use? A systematic review
}

To cite: Taylor ML, Thomas EE, Snoswell CL, et al. Does remote patient monitoring reduce acute care use? $\mathrm{A}$ systematic review. BMJ Open 2021;11:e040232. doi:10.1136/ bmjopen-2020-040232

- Prepublication history and supplemental material for this paper is available online. To view these files, please visit the journal online (http://dx.doi. org/10.1136/bmjopen-2020040232).

Received 10 May 2020 Revised 01 February 2021 Accepted 10 February 2021

Check for updates

(C) Author(s) (or their employer(s)) 2021. Re-use permitted under CC BY-NC. No commercial re-use. See rights and permissions. Published by BMJ.

Centre for Online Health, Centre for Health Services Research, The University of Queensland, Woolloongabba, Queensland, Australia

Correspondence to Associate Professor Liam J Caffery; I.caffery@uq.edu.au

Monica L Taylor (D), Emma E Thomas (D), Centaine L Snoswell (D), Anthony C Smith (D), Liam J Caffery

\section{ABSTRACT}

Objective Chronic diseases are associated with increased unplanned acute hospital use. Remote patient monitoring (RPM) can detect disease exacerbations and facilitate proactive management, possibly reducing expensive acute hospital usage. Current evidence examining RPM and acute care use mainly involves heart failure and omits automated invasive monitoring. This study aimed to determine if RPM reduces acute hospital use.

Methods A systematic literature review of PubMed, Embase and CINAHL electronic databases was undertaken in July 2019 and updated in 0ctober 2020 for studies published from January 2015 to October 2020 reporting RPM and effect on hospitalisations, length of stay or emergency department presentations. All populations and disease conditions were included. Two independent reviewers screened articles. Quality analysis was performed using the Joanna Briggs Institute checklist. Findings were stratified by outcome variable. Subgroup analysis was undertaken on disease condition and RPM technology.

Results From 2050 identified records, 91 studies were included. Studies were medium-to-high quality. RPM for all disease conditions was reported to reduce admissions, length of stay and emergency department presentations in $49 \%(n=44 / 90), 49 \%(n=23 / 47)$ and $41 \%$ $(n=13 / 32)$ of studies reporting each measure, respectively. Remaining studies largely reported no change. Four studies reported RPM increased acute care use. RPM of chronic obstructive pulmonary disease (COPD) was more effective at reducing emergency presentation than RPM of other disease conditions. Similarly, invasive monitoring of cardiovascular disease was more effective at reducing hospital admissions versus other disease conditions and non-invasive monitoring.

Conclusion RPM can reduce acute care use for patients with cardiovascular disease and COPD. However, effectiveness varies within and between populations. RPM's effect on other conditions is inconclusive due to limited studies. Further analysis is required to understand underlying mechanisms causing variation in RPM interventions. These findings should be considered alongside other benefits of RPM, including increased quality of life for patients.

PROSPERO registration number CRD42020142523.

\section{INTRODUCTION}

Many people find it challenging to selfmanage complex and comorbid conditions and identify warning signs of exacerbation.

\section{Strengths and limitations of this study}

This systematic review was not limited by disease condition and gives an overall picture on the effect of remote patient monitoring on acute care hospital use.

- We have included subanalyses and new evidence, particularly for patients with chronic obstructive pulmonary disease and monitoring using implanted devices.

- Due to heterogeneity of included studies we were unable to perform a meta-analysis.

Healthcare providers often only become aware of a decline in an individual's condition once symptoms have become severe enough to require escalation to acute care. This scenario may be avoided by using remote patient monitoring (RPM).

RPM or telemonitoring refers to the recording and transmission of patient biometrics, vital signs and/or disease-related data to a healthcare provider using information and communications technology. ${ }^{1}$ RPM data are disease-specific and commonly include measurements like blood pressure, weight, heart rate, respiration rate, pulse oximetry, spirometry, temperature, blood glucose levels or specific symptoms. ${ }^{2}$ Data can be collected automatically (eg, by an implanted or wearable devices) or manually collected by the patient using peripheral devices and a transmission hub. RPM interventions for cardiovascular disease (CVD) can be either invasive or non-invasive. Invasive interventions involve direct measurement of biometric data, such as heart rate and pulmonary artery pressures by an implanted device, which are then transmitted to the healthcare provider. Examples of implanted devices include pacemakers which are used to regulate abnormal rhythms, and implantable cardioverter defibrillators (ICDs) which are used in patients at high risk of cardiac arrest (eg, ventricular tachycardia or fibrillation). ${ }^{3}$ Non-invasive interventions involve the transmission of data, 
such as body weight, blood pressure or pulse oximetry ${ }^{4}$ and are used commonly in patients that require longterm self-management support (eg, patients with heart failure) ${ }^{5}$ Review of transmitted data may be active, which occurs when a remote healthcare provider regularly reviews patient data. Alternatively, it may be passive when the healthcare provider is only alerted if data readings reach a pre-determined clinical threshold. Interventions resulting from an abnormal data reading or data indicative of a decline in condition may include telephone support, video consultation or home visits.

Chronic diseases are associated with high rates of unplanned acute hospital use, even more so when the patient has comorbid conditions. ${ }^{6}$ This represents a substantial cost to the health system. For example, in Australia there are more than 748000 potentially avoidable hospitalisations per year, of which nearly half $(46 \%)$ were due to chronic conditions such as congestive cardiac failure, diabetes complications, chronic obstructive pulmonary disease (COPD) and angina. ${ }^{7}$ Early detection and proactive management of chronic disease exacerbations may result in decreased costly acute hospital use. Previous studies have demonstrated that RPM can effectively alert a healthcare team to a decline in a person's condition enabling issues to be resolved out of hospital thereby reducing the need for urgent hospital admissions. ${ }^{8}$ Existing research shows that for RPM to be costeffective it needs to reduce acute hospital use. ${ }^{9}$ There have been a number of disease-specific reviews (such as for heart failure and COPD) that have reported effect of RPM on acute hospital use, however this is often a secondary outcome..$^{50-14}$ Furthermore, these reviews were largely published more than 5 years ago. Hence, there is limited evidence for the effect of RPM using newer technologies such as implanted devices and for other disease conditions. ${ }^{15}$ With numbers of new RPM technologies substantially increasing in research trials and in the marketplace, more regular reviews of the literature are warranted. The aim of this study is to provide a contemporary evidence synthesis that will determine if the latest RPM tools being used across condition types are reducing acute hospital use.

\section{METHODS}

In order to achieve the aims of this study we conducted a systematic review of publications from the last 5 years (2015-2020). Supporting our decision to examine research from the last 5 years only was a recent systematic review reporting $43 \%$ of remote monitoring studies were published from 2015 on, and over $60 \%$ of Oxford Level of Evidence 1 papers were published post-2015. ${ }^{16}$ The protocol for our review was registered with PROSPERO, international prospective register of systematic reviews. ${ }^{17}$

\section{Search strategy}

To identify relevant articles we conducted searches of three electronic databases: PubMed (MEDLINE) (1966-2020),
Box 1 Example search strategy (PubMed)

("Hospitalization"[MeSH] OR "length of stay"[All Fields] OR ("hospitalization"[All Fields] OR "hospitalization"[MeSH Terms] OR "hospitalization"[All Fields]) OR admission[All Fields]] OR presentation[All Fields]) AND

("Remote monitoring"[All Fields] OR "Remote patient monitoring"[All Fields] OR (Inhome[All Fields] AND monitoring[All Fields]) OR "Inhome monitoring"[All Fields] OR "Home telehealth"[All Fields] OR Telemonitoring[All Fields] OR Telecare[All Fields])

AND

((Case Reports[ptyp] OR Clinical Study[ptyp] OR Clinical Trial[ptyp] OR Clinical Trial, Phase I[ptyp] OR Clinical Trial, Phase II[ptyp] OR Clinical Trial, Phase III[ptyp] OR Clinical Trial, Phase IV[ptyp] OR Comparative Study[ptyp] OR Controlled Clinical Trial[ptyp] OR Evaluation Studies[ptyp] OR Introductory Journal Article[ptyp] OR Journal Article[ptyp] OR MetaAnalysis[ptyp] OR Multicenter Study[ptyp] OR Observational Study[ptyp] OR Randomized Controlled Trial[ptyp] OR Validation Studies[ptyp]) AND English[lang])

Embase (OvidSP) (1974-2020) and CINAHL (EBSCOhost) (1982-2020). Boolean search terms (box 1) were developed with the assistance of a university librarian and used a combination of medical subject headings (MeSH) and keywords related to remote monitoring, telemedicine and acute care utilisation. Searches were first conducted in July 2019 and updated in October 2020.

\section{Inclusion/exclusion criteria}

We included primary, empirical studies including randomised controlled trials (RCTs), cohort studies and case-control studies that compared acute hospital use by patients undergoing RPM with those not remotely monitored, or studies that compared acute hospital use preRPM and post-RPM. Acute hospital use for the purpose of this review is defined as hospital admissions (including readmissions), length of stay and emergency department (ED) presentations. Patients could be monitored for any disease condition as long as the monitored data was sent to a clinician for review (ie, self-monitoring was excluded) and the patient was monitored while outside of a hospital setting. A variety of RPM technology was eligible for inclusion such as non-invasive peripheral measurement devices, invasive cardiac implantable electronic devices and manual data entry using tablets, smartphones or websites. Only English language articles where the fulltext was available were included.

Interventions that did not involve a disease condition (eg, those with a focus on monitoring physical activity) were excluded. Studies that used simulated or modelled data were excluded, as were reviews, non-experimental studies, conference abstracts, and commentaries.

\section{Selection}

Titles and abstracts were screened independently by two researchers (MLT and Maryama Bihi) who were also blinded to each other's selections. Where necessary the full text was used to determine eligibility. A third 


\begin{tabular}{|c|c|}
\hline Variable & Description \\
\hline First author & $\begin{array}{l}\text { Surname of the first author of the } \\
\text { publication }\end{array}$ \\
\hline Year & Year of publication \\
\hline Country & Country where research was conducted \\
\hline Study type & $\begin{array}{l}\text { Study design as cohort, randomised } \\
\text { controlled trial, quasi-experimental or } \\
\text { case-control }\end{array}$ \\
\hline Patient group & Medical condition of study participants \\
\hline Comorbidities & $\begin{array}{l}\text { Whether or not the authors mentioned } \\
\text { participants having comorbidities }\end{array}$ \\
\hline $\begin{array}{l}\text { Data being } \\
\text { monitored }\end{array}$ & $\begin{array}{l}\text { Patient vitals measured using remote } \\
\text { monitoring (eg, blood pressure, heart rate) }\end{array}$ \\
\hline Trial length & $\begin{array}{l}\text { Length of time a patient was remotely } \\
\text { monitored (number of months) }\end{array}$ \\
\hline Sample size & $\begin{array}{l}\text { Number of participants in the research, } \\
\text { listed by intervention and control groups }\end{array}$ \\
\hline Mean age & $\begin{array}{l}\text { The average or mean age of the } \\
\text { intervention and control groups as reported } \\
\text { by authors }\end{array}$ \\
\hline Gender split & $\begin{array}{l}\text { Percentage of male and female participants } \\
\text { in the study }\end{array}$ \\
\hline RPM device & $\begin{array}{l}\text { Device used for remote monitoring (eg, } \\
\text { tablet, dedicated remote monitoring unit) }\end{array}$ \\
\hline Data collection & $\begin{array}{l}\text { Whether biometric data was collected } \\
\text { manually or automatically }\end{array}$ \\
\hline Data review & $\begin{array}{l}\text { Whether biometric data was reviewed by } \\
\text { clinical staff passively (eg, there was an } \\
\text { automated alert system) or actively (eg, } \\
\text { nurse checks dashboard each day) }\end{array}$ \\
\hline $\begin{array}{l}\text { Supplementary } \\
\text { support mode }\end{array}$ & $\begin{array}{l}\text { If support from clinical staff beyond event } \\
\text { management or routine visits occurred, } \\
\text { what was the mode of contact used }\end{array}$ \\
\hline Outcome type & $\begin{array}{l}\text { Whether the outcome reported was for } \\
\text { all cause, condition-specific, both or not } \\
\text { specified }\end{array}$ \\
\hline $\begin{array}{l}\text { Outcome } \\
\text { findings }\end{array}$ & $\begin{array}{l}\text { Results of the investigation (significant } \\
\text { or not significant increase or decrease } \\
\text { in acute care use and effect size where } \\
\text { available) }\end{array}$ \\
\hline Summary & $\begin{array}{l}\text { Overall summary of whether remote } \\
\text { monitoring increased, decreased or had no } \\
\text { significant effect on acute care use in the } \\
\text { study }\end{array}$ \\
\hline
\end{tabular}

RPM, remote patient monitoring.

researcher (CLS, EET or LJC) decided on inclusion when consensus was not reached.

\section{Data extraction}

Data was extracted from the full text of the articles and recorded on a data extraction form. A description of data extraction variables can be found in table 1 . One author (MLT) extracted the data and a second author (EET) validated the accuracy by checking a $20 \%$ random selection of the data.

\section{Quality assessment}

Quality of the included studies was assessed using the Joanna Briggs Institute (JBI) critical appraisal checklists. ${ }^{18}$ This suite of checklists has individual templates based on study design. Specific checklists have different numbers of questions. The appropriate checklist was chosen using an algorithm for classifying study design. ${ }^{19}$ To allow comparison across study design, the number of checklist items that received a 'yes' was converted to a proportion of the total number of questions. Based on the 'yes' proportions, studies were categorised as high $(80 \%$ and over), medium $(60 \%-79 \%)$ or low $(<60 \%)$ quality.

Two researchers (MLT and EET) completed quality assessment on each article and scores were compared and consensus reached via discussion. When a publication reported outcomes both related and not related to acute care use, the quality assessment score was based on the measurement of the acute care use outcomes specifically. No articles were excluded from this review based on their quality score.

\section{Analysis}

Findings from included article were stratified by acute care use as admissions, ED presentations or length of stay. Findings were categorised by the author's conclusion on increased, decreased or no change on acute hospital use. Changes in use that were not statistically significant were categorised as no change. Subgroup analysis was undertaken on disease condition and technology category permutations (ie, invasive vs non-invasive).

Due to the heterogeneity in population groups, intervention designs and outcome measures findings were synthesised narratively. Findings were reported in accordance with the Preferred Reporting Items for Systematic Reviews and Meta-Analyses (PRISMA) guidelines. ${ }^{20}$

\section{RESULTS}

\section{Study selection}

Ninety-one articles were included in this review. The results of each stage of search and selection process are shown in the PRISMA diagram (figure 1).

\section{Study characteristics}

Included studies were primarily conducted in Europe $(\mathrm{n}=52,57 \%)$, followed by the USA $(\mathrm{n}=26,29 \%)$. Most studies were RCTs $(n=45,50 \%)$ or cohort studies $(n=34$, $37 \%)$, with nine quasi-experimental studies $(10 \%)$ and three case-controls $(3 \%)$.

The sample size of patients ranged from $25^{21}$ to $92566^{22}$ with the majority of included studies $(\mathrm{n}=68,75 \%)$ having a sample size of greater than 100 participants (intervention and control arms combined). Follow-up time was longer than 6 months in the majority of studies $(n=62,68 \%)$, however, 12\% ( $\mathrm{n}=11)$ had a follow-up time of 3 months 


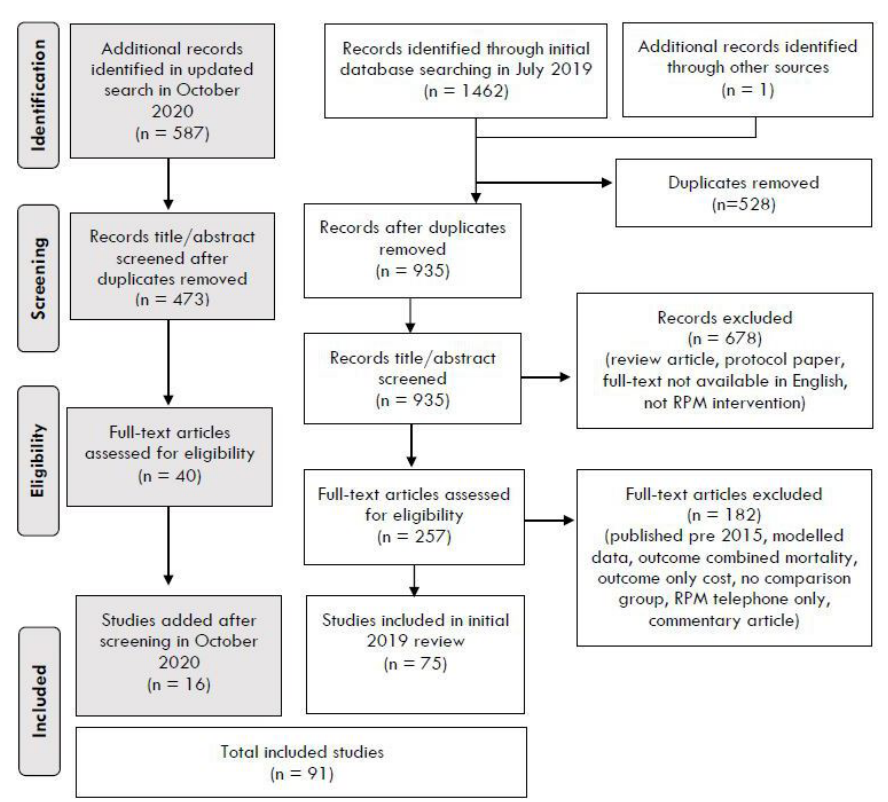

Figure 1 Preferred Reporting Items for Systematic Reviews and Meta-Analyses flow diagram of screening process and study selection. RPM, remote patient monitoring.

or less. Thirty-two studies (35\%) included $>70 \%$ male participants. Gender bias was commonly observed in many CVD trials despite similar numbers of deaths across both genders. ${ }^{23}{ }^{24}$ All interventions, except one study on infants with heart disease, were targeted at adults. Acute hospital use was reported for all causes $(n=18,20 \%)$, only the remotely monitored condition $(n=21,23 \%)$, both the all cause and the disease-specific condition $(n=30,33 \%)$ or was not specified $(\mathrm{n}=22,24 \%)$.

Characteristics of all included studies are summarised in online supplemental table 1 .

\section{Intervention characteristics}

\section{Disease conditions}

The patient populations in the included studies were mostly people with CVD $(\mathrm{n}=54,59 \%)$, COPD $(\mathrm{n}=18,20 \%)$ or comorbid CVD and COPD $(n=4,4 \%)$. Of these, invasive monitoring was used for 22 studies and non-invasive monitoring was used in 30 studies. Remaining studies $(\mathrm{n}=15,17 \%)$ had varying study populations including nursing home residents, patients with schizophrenia, peritoneal dialysis patients, inflammatory bowel disease and individuals on home ventilation.

\section{Remote monitoring processes}

The most common biometrics that were remotely monitored were heart rate $(n=52,57 \%)$, blood pressure $(n=49$, $54 \%)$, weight $(\mathrm{n}=44,48 \%)$ and oxygen saturation $(\mathrm{n}=39$, $43 \%)$. Cardiac implantable electronic devices (CIEDs) $(\mathrm{n}=22,24 \%)$ can enable automated transmission of data, monitor heart rhythm, alert if an arrhythmic episode occurs and check the device function.

A comparison of data being monitored in each study can be seen in online supplemental table 2 .
The non-invasive interventions $(\mathrm{n}=69,76 \%)$ required manual data collection performed by the patient or support person. Clinical review of biometrics was evenly split between those that had passive review (ie, automated alert) and those that had active data review (eg, clinician logging into system to review patient data daily). Typically, manual data collection was actively reviewed by a nurse or other clinician once per day.

In all studies out-of-range biometrics triggered clinical communication. Some interventions involved supplementary services from staff, such as assisting with education and health literacy. Modes of communication with patients included telephone $(\mathrm{n}=37,41 \%)$, videoconference $(\mathrm{n}=13,14 \%)$ and asynchronous methods such as SMS or email $(n=10,11 \%)$.

\section{Technology}

The technology for RPM was either a dedicated unit or hub ( $\mathrm{n}=35,39 \%)$; CIEDs including ICDs, cardiac resynchronisation therapy (CRT) including those with defibrillators (CRT-Ds) and pacemakers ( $\mathrm{n}=22,24 \%)$; tablet computer applications $(\mathrm{n}=13,14 \%)$; telephone or smartphone applications $(n=9,10 \%)$; websites $(n=4,4 \%)$; or other technologies such as an electronic health diary, inhaler or medication device $(n=8,9 \%)$. Forty studies explicitly stated the patient used peripheral devices such as weight scales, pulse oximeters, and thermometers.

\section{Effect of remote monitoring on acute care use}

RPM for all disease conditions was reported to have reduced admissions, length of stay and ED presentations in $49 \%(n=44$ of 90$), 49 \%(n=23$ of 47$)$ and $41 \%(n=13$ of 32) of studies, respectively, for studies that reported each measure of acute care use. The remaining studies largely reported no change in acute care use for remotely monitored patients. A very small number of studies reported RPM increased acute care use (figures 2-4). The majority of studies set a significance level of $5 \%$ for concluding

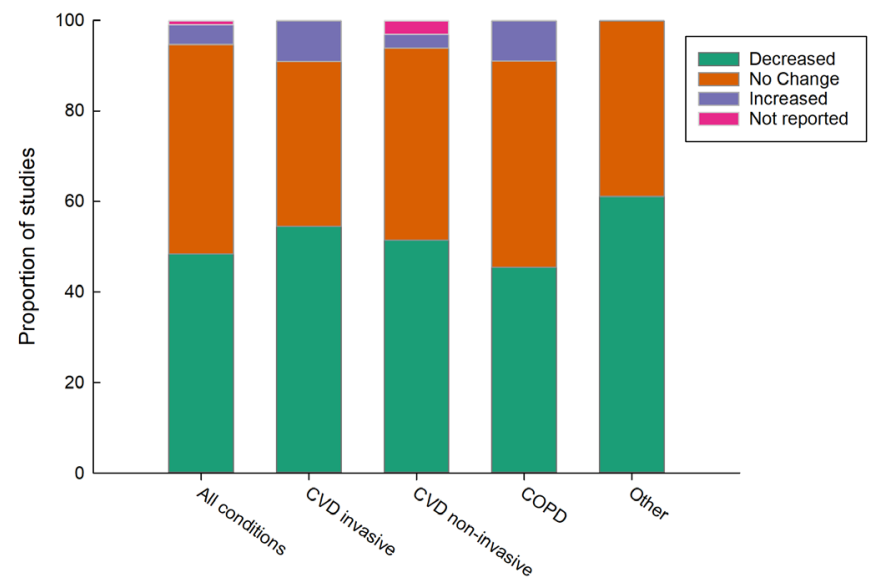

Figure 2 Effect of remote patient monitoring on hospitalisation by condition type. COPD, chronic obstructive pulmonary disease; CVD, cardiovascular disease. 


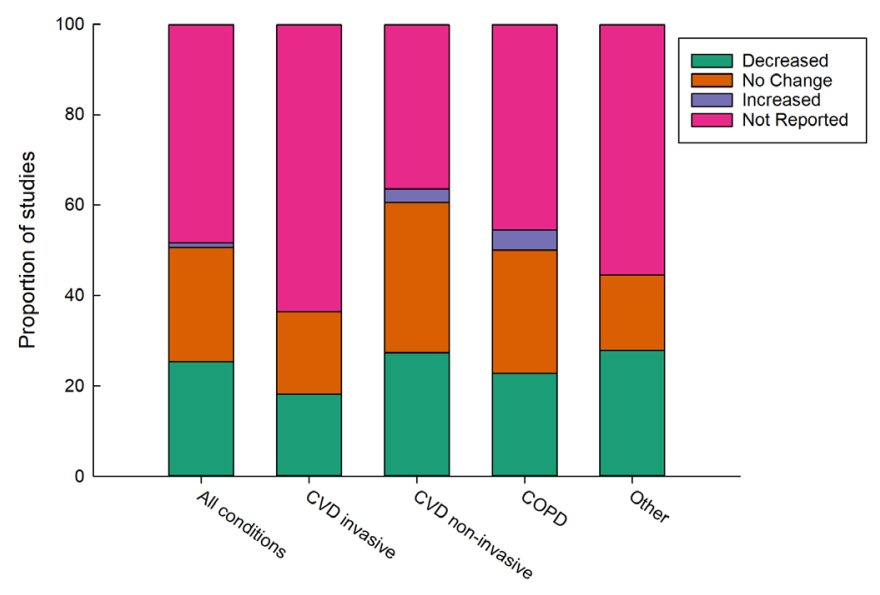

Figure 3 Effect of remote patient monitoring on length of stay by condition type. COPD, chronic obstructive pulmonary disease; CVD, cardiovascular disease.

that there was a difference between groups, however individual study details on this can be viewed in online supplemental table 1.

\section{CVD invasive}

CVD using invasive monitoring appears to be most effective at reducing hospitalisations (figure 2). Eleven RCTs have been conducted. ${ }^{25-35}$ Of these, only three demonstrated a significant reduction in acute care use with a reduction in length of hospital stays ${ }^{26}$ by 2.5 days ( $\mathrm{RPM}=10.3 \pm 8.1$ days, median: 8.0 days vs non-monitored group $=17.5 \pm 19.9$ days, median 10.5 days, $\mathrm{p}=0.027$ ) and lower hospitalisation rates in the monitored group $(37.1 \%$ vs $45.5 \%, \mathrm{p}=0.045^{31}$; hazard ratio (HR) 0.6, 0.42-0.79, $\mathrm{p}=0.002) .{ }^{35}$ All remaining RCTs $(\mathrm{n}=6,55 \%)$ showed no significant effect. Of the eight cohort studies conducted with invasive monitoring, five $(63 \%)$ showed a significant reduction in hospital use. Two of these ${ }^{22} 36$ had very large

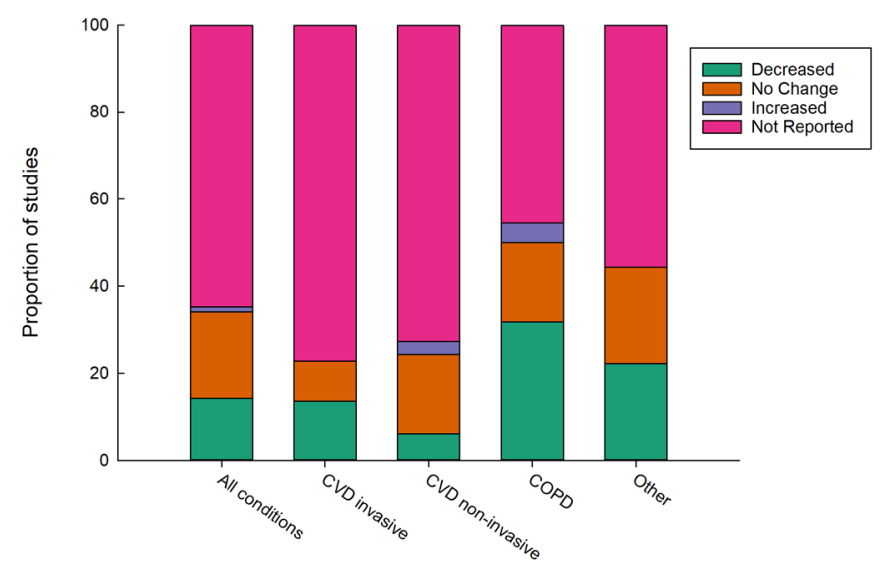

Figure 4 Effect of remote patient monitoring on emergency department presentations by condition type. COPD, chronic obstructive pulmonary disease; CVD, cardiovascular disease. sample sizes with matched controls ( $\mathrm{n}=37742$ and 92566 , respectively). In fact, Piccini $e t a l^{22}$ had a larger sample size $(\mathrm{n}=92566)$ than all the other CVD invasive populations combined $(\mathrm{n}=49113)$. Both Piccini $e t a l^{22}$ and Akar et $a \hat{l}^{36}$ reported an $18 \%$ lower risk of all-cause hospitalisation in the RPM groups with both studies reporting identical adjusted HRs of 0.82 (95\% CI: 0.80 to 0.84; p value: $<0.001)$. Piccini $e t a l^{22}$ also reported a shorter mean length of hospital stay of approximately 3 days ( 5.3 days vs 8.1 days; $\mathrm{p}<0.001)$. These reductions were preserved for all implanted device types (pacemakers, ICDs and CRT) but were maximal in CRT participants. By contrast Ladapo $e t a l^{37}$ reported the most pronounced benefits of hospital use in patients with ICDs.

\section{CVD non-invasive}

Most RCTs investigating the impact of non-invasive RPM were for heart failure populations $(n=15,37 \%)$. Findings from these studies have been mixed with eight trials $(53 \%)$ reporting no difference and seven trials (47\%) reporting a reduction in acute hospital use. The largest RCT included in this review reported the RPM group spent approximately 2 days less in hospital compared with control participants (RPM group=mean 3.8 days per year, $95 \%$ CI: 3.5 to 4.1 vs 5.6 days per year, $95 \%$ CI: 5.2 to 6.0) ${ }^{38}$ However, similarly large RCTs reported no change in the number of hospitalisations or length of stay. ${ }^{39} 40$ Studies varied in regard to the precise population investigated, the duration of RPM, the type of devices used and the intensity and timing of the interaction. Koehler et al provided the first structured RPM intervention that used a holistic approach including multiple healthcare providers (eg, cardiologist, general practitioner (GP), nurse) and tailored support using a predefined algorithm. ${ }^{38}$

\section{Chronic obstructive pulmonary disease}

RPM of COPD appears to be most effective at reducing ED presentations (figure 4). Of the 13 RCTs investigating RPM in COPD populations, seven trials (54\%) showed no significant difference in hospital use between the intervention and control groups and approximately $30 \%$ reported a reduction in hospital use. Two reported an increase in hospital admissions in the RPM group; ${ }^{41} 42$ Witt Udsen $e t$ $a t^{42}$ had the largest sample size ( $\mathrm{n}=578 / 647$ intervention/ control) of the trials. Across the RCTs, COPD-related hospitalisations differed from a mean difference of 10 fewer admissions in the intervention group of Sink $e t a t^{43}$ over 8 months (absolute risk reduction $=11.6 \%$; RPM $=6$ hospitalisations vs non-monitored $=16$ hospitalisations) to a slight increase in admissions over a 6-month period ( RPM admissions $=0.63$ vs 0.32 in non-monitored mean difference: $0.32, \mathrm{p}$ value: 0.026$).{ }^{41}$ All cohort studies $(n=9)$ reported a reduction in at least one measure of acute hospital use. Of these the largest sample size $(\mathrm{n}=651 / 7047$ intervention/control) and over a 12-month period reported a lower proportion of patients hospitalised due to all-causes $(-15.16 \%, \mathrm{p}<0.0001)$, and COPDspecific admissions $(-20.27 \%, \mathrm{p}<0.0001) .{ }^{44} \mathrm{On}$ average, 


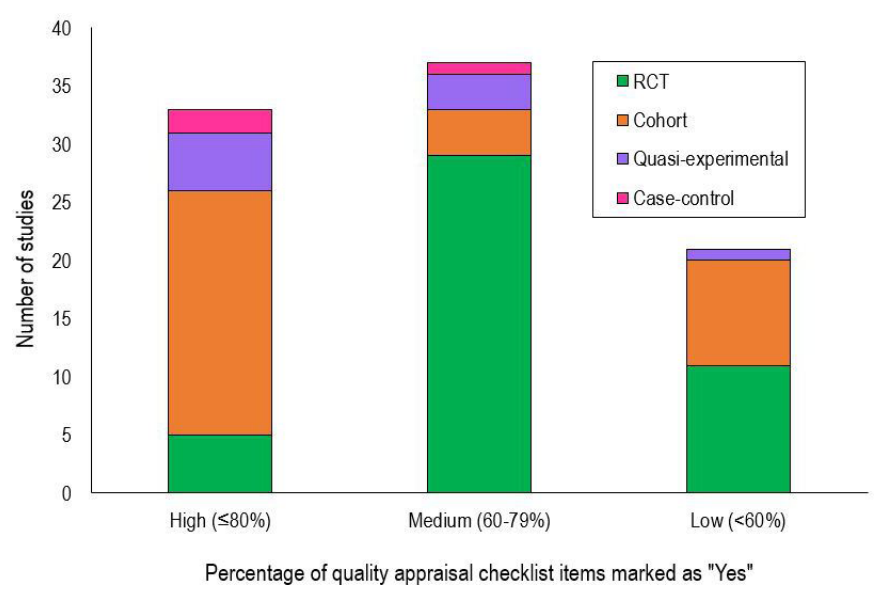

Figure 5 Number of articles by proportion of 'Yes' responses to items on the Joanna Briggs Institute critical appraisal checklists, separated by study type. RCT, randomised controlled trial.

people in the RPM group spent $3.1(\mathrm{p}<0.0001)$ and 2.07 $(\mathrm{p}<0.001)$ fewer days in hospital due to all causes and COPD, respectively, than the control group.

\section{Other conditions}

The current RPM literature to date is dominated by adult CVD and COPD populations. It is worth noting that beneficial effects of RPM have been observed in some other conditions. Notably, one study demonstrated a significant reduction in hospital admission among infants with single ventricular heart disease (relative risk of hospital use in the control group: 2.19, 95\% CI: 1.16 to 4.12 , $\mathrm{p}=0.016) .{ }^{45}$ Reductions in hospital use were also seen in RPM groups with multiple chronic conditions; ${ }^{46}$ mental health; ${ }^{478}$ and patients with home-ventilated neuromuscular conditions. ${ }^{49}$

\section{Study quality}

The overall quality of studies as assessed by the JBI critical appraisal checklists was medium to high (figure 5). ${ }^{18}$ The quality of RCTs was most often compromised by participant outcomes being assessed by someone who was not blinded to the control or intervention group. However, it can be challenging to blind an assessor or participant in this type of intervention. In cohort studies, the quality was compromised by incomplete follow. Only one-third of the studies had clearly done so, while the remaining two-thirds either did not address incomplete follow-up or it was unclear.

\section{DISCUSSION}

\section{Principal findings}

This systematic review found around half of 91 included studies reported RPM decreased hospital admissions and around half reported no change. A smaller number of studies reported the effect of RPM on length of stay $(n=47)$ and ED presentations $(n=32)$, with around half reporting a decrease and half reporting no change for both of these measures of acute hospital use. RPM of COPD was more effective at reducing ED presentation than RPM of other disease conditions. Similarly, invasive monitoring of CVD was more effective at reducing hospital admissions compared with other disease conditions and non-invasive monitoring. Only four studies reported higher acute hospital use resulting from RPM. ${ }^{32414250}$ Around 70\% of included studies were for CVD, COPD or comorbid CVD and COPD. RPM for lesser studied populations including mental health and neuromuscular conditions, appears feasible but findings on acute hospital use is inconclusive due to the limited number of studies. Study quality as appraised by the JBI critical appraisal checklist was considered medium to high.

A strength of this study when compared with other reviews was the inclusion of all disease conditions, monitoring types and study designs. The broad inclusion categories has allowed analysis of RPM on disease conditions beyond those published on heart failure, previously excluded studies (eg, cohort studies) and comparison of effectiveness of different RPM interventions. While RCTs are considered the gold-standard experimental design, restricting to RCTs excludes large scale cohort studies, which can provide both strong evidence and are more applicable to real-world settings. For example, the Parthiban et a $\overrightarrow{l^{3}}$ meta-analysis is, to the best of our knowledge, the only review that reports the impact on hospital admissions resulting from invasive cardiac monitoring. This study found no significant reduction in admissions, however, findings from a large scale cohort study ( $\mathrm{n}=34259 / 58307$ intervention/control) by Piccini et $a l^{22}$ found that invasive cardiac monitoring significantly reduced both all-cause hospitalisations and the resultant length of stay

There has been a number of previous reviews of RPM for COPD populations. ${ }^{13} 15$ One included six primary studies (both RCTs and other study designs) of which four reported reduction in hospital admissions. ${ }^{15}$ Our review included 22 studies on RPM of COPD and comorbid COPD populations. Our findings were consistent when comparing the effect on hospital admissions. However, in addition we found a reduction in ED presentations in around half of the studies. Two of the four studies that reported RPM resulted in increased acute care use were in COPD populations. This increase may be explained by the perception that predicting COPD exacerbations based on variations in spirometry and other physiological measures continues to be a challenge resulting in high rates of false positive warnings in this cohort. ${ }^{44}$

\section{Implications for practice}

\section{Effect of RPM on subpopulations}

Clinical outcomes for patients on remote monitoring have been more effective for subpopulations when compared with the whole of population. The largest study to date, ${ }^{22}$ reported that RPM was associated with reductions in allcause hospitalisation. While this association held across all implanted devices, it was most evident for cardiac 
resynchronisation therapy patients, suggesting that sicker patients are the most likely to benefit. Furthermore, the greater effectiveness of invasive RPM may result from the continuous generation of biometric measurements. Whereas, non-invasive monitoring produces intermittent measurements. The safety of implanted devices can also be checked remotely using RPM to identify any device or lead malfunctions earlier. ${ }^{36}$ Notably, no study in this review reported adverse events related to patient safety. This review has also demonstrated that the way remote monitoring services are implemented are highly variable and intervention characteristics could be a determinant of outcomes. For example, patients using smartphone applications were shown to have better compliance to monitoring than those using a web page. ${ }^{51}$ Further to this, the severity of disease can also be a determining factor of how effective an RPM intervention will be in reducing acute care use. ${ }^{13}$

\section{Importance of a patient-centric approach}

RPM interventions are complex and require careful patient selection along with appropriate technology that accurately alerts healthcare staff and results in a timely response. Additionally, how RPM might improve a patient's health literacy and self-efficacy to manage their condition is likely to be highly important. ${ }^{52}$ Supportive of this theory is one author who postulated this was due to participants becoming dependant on the RPM systems and telemonitoring nurse rather than developing the appropriate skills to self-manage.$^{53}$ A patient-centred approach that enables seamless interaction between patients and the healthcare system is likely to influence RPM success. This is demonstrated well by the comprehensive approach Koehler $e t$ $a l^{88}$ took by involving multiple healthcare providers (eg, cardiologist, GP, nurse) and using an algorithm to tailor support to participants resulting in positive results for people with heart failure.

Many studies reported that RPM increased quality of life, improved the timeliness of atrial fibrillation detection and improved communication. ${ }^{5} 124054$ Focusing on effect of acute care use, may result in overlooking ancillary benefits of RPM.

There appears to be a lack of studies for some highly prevalent chronic conditions such as diabetes. This may be explained by the fact that exacerbation of diabetes is less likely to result in acute hospital use relative to CVD or COPD; and therefore studies on the effect of remote monitoring of diabetes do not use acute hospital use as an outcome measure.

\section{Limitations}

Findings of this review should be interpreted in light of some limitations. First, publication bias is possible with selective reporting of studies with findings of reduced acute hospital use. The included studies were highly heterogeneous in terms of patient groups (eg, comorbidities), intervention (eg, inclusion of educational component, invasive vs non-invasive monitoring, active vs passive review) and study differences (eg, all-cause vs diseasespecific acute hospital use). This makes generalisability of findings difficult. Due to heterogeneity and inability to perform a meta-analysis we used proportion of studies reporting a decrease in acute hospital use as a measure of comparative effectiveness. Differences in the control population may also lead to very different rates of admissions and influence whether or not a significant effect is found. For example, Boriani $e t a l^{34}$ compared two trials and found that 1-year mortality in the control-arm of each trial differed by nearly a factor of two. Finally, a study that uses patient self-reported acute hospital use may be less rigorous than those that used a retrospective approach supported by activity data, due to patient recall bias. ${ }^{55}$

\section{Future research}

Further investigation is needed to identify subpopulations and intervention characteristics that will enhance the effectiveness of remote monitoring. Policymakers and funders also need to understand if remote monitoring is cost-effective. It is important for implementation of RPM interventions to consider costs from a system perspective. It would be wrong to assume that reducing admissions reduces costs, as there is potential of increasing collateral health system usage (eg, to outpatient care). Economic analysis is also needed to consider the cost of implementing and operating RPM interventions as opposed to only comparing the direct cost of acute care use. ${ }^{56}$

\section{CONCLUSION}

This review has shown that RPM of CVD and COPD can reduce hospital admissions, length of stay and emergency presentation in around half of the interventions and results in no change in acute care usage in the remaining. Increased acute care use was rarely reported. The effect of RPM for other disease conditions is inconclusive due to the limited number of studies in these areas. Clinical outcomes for patients on remote monitoring have been more effective for subpopulations when compared with the whole of population. RPM of COPD was more effective at reducing ED presentation than RPM of other disease conditions. Invasive monitoring of CVD was more effective at reducing hospital admissions compared with other disease conditions and non-invasive monitoring. This may be in part due to the ability of implantable devices to continuously monitor a person and automatically transmit data. Implantable devices have advanced ability to directly detect cardiac issues (eg, atrial fibrillation) rather than relying on physiological signs (eg, changes in weight or blood pressure) that may or may not be due to the underlying cardiac condition. Further research is required to understand the underlying mechanisms causing such variation in RPM studies. Findings from this review should be considered alongside other benefits of RPM including increased quality of life and autonomy for patients. 
Twitter Centaine L Snoswell @csnoswell and Liam J Caffery @DrLiamCaffery

Acknowledgements The authors would like to thank Julie Hansen, Senior Librarian from UQ Library, for her assistance in developing the search strategy for this systematic review. They would also like to thank Ms Maryama Bihi for her assistance in screening titles and abstracts.

Contributors This research was conceptualised by LJC. MLT, EET, CLS, ACS and LJC contributed to the study design. Searches and data extraction carried out by MLT and EET under guidance from CLS and LJC. Data analysis was performed by MLT, EET and LJC. Manuscript was drafted by MLT, EET and LJC. Critical review of manuscript was undertaken by all authors. All authors approved the final manuscript.

Funding This research is conducted for the NHMRC Partnership Centre for Health System Sustainability (Grant ID \#: 9100002) administered by the Australian Institute of Health Innovation, Macquarie University. Along with the NHMRC, the funding partners in this research collaboration are: The Bupa Health Foundation; NSW Ministry of Health; Department of Health, WA; and The University of Notre Dame Australia. Their generous support is gratefully acknowledged. While the NHMRC The Bupa Health Foundation, NSW Ministry of Health, Department of Health, WA and The University of Notre Dame Australia, have provided in-kind and financial support for this research, they have not reviewed the content and are not responsible for any injury, loss or damage however arising from the use of, or reliance on, the information provided herein. The published material is solely the responsibility of the authors and does not reflect the views of the NHMRC or its funding partners. EET is supported by a Postdoctoral Fellowship (105215) from the National Heart Foundation of Australia.

Competing interests None declared.

Patient consent for publication Not required.

Provenance and peer review Not commissioned; externally peer reviewed.

Data availability statement All data relevant to the study are included in the article or uploaded as supplemental information.

Supplemental material This content has been supplied by the author(s). It has not been vetted by BMJ Publishing Group Limited (BMJ) and may not have been peer-reviewed. Any opinions or recommendations discussed are solely those of the author(s) and are not endorsed by BMJ. BMJ disclaims all liability and responsibility arising from any reliance placed on the content. Where the content includes any translated material, BMJ does not warrant the accuracy and reliability of the translations (including but not limited to local regulations, clinical guidelines, terminology, drug names and drug dosages), and is not responsible for any error and/or omissions arising from translation and adaptation or otherwise.

Open access This is an open access article distributed in accordance with the Creative Commons Attribution Non Commercial (CC BY-NC 4.0) license, which permits others to distribute, remix, adapt, build upon this work non-commercially, and license their derivative works on different terms, provided the original work is properly cited, appropriate credit is given, any changes made indicated, and the use is non-commercial. See: http://creativecommons.org/licenses/by-nc/4.0/.

\section{ORCID iDs}

Monica L Taylor http://orcid.org/0000-0001-5333-2955

Emma E Thomas http://orcid.org/0000-0001-8415-0521

Centaine L Snoswell http://orcid.org/0000-0002-4298-9369

Anthony C Smith http://orcid.org/0000-0002-7756-5136

Liam J Caffery http://orcid.org/0000-0003-1899-7534

\section{REFERENCES}

1 The American Telemedicine Association. Telemedicine, telehealth, and health information technology, 2006. Available: https://www.who. int/goe/policies/countries/usa_support_tele.pdf?ua=1 [Accessed 3 Dec 2020].

2 Malasinghe LP, Ramzan N, Dahal K. Remote patient monitoring: a comprehensive study. J Ambient Intell Humaniz Comput 2019;10:57-76.

3 Parthiban N, Esterman A, Mahajan R, et al. Remote monitoring of implantable cardioverter-defibrillators: a systematic review and metaanalysis of clinical outcomes. J Am Coll Cardiol 2015;65:2591-600.

4 Vegesna A, Tran M, Angelaccio M, et al. Remote patient monitoring via non-invasive digital technologies: a systematic review. Telemed $\mathrm{J}$ E Health 2017;23:3-17.
5 Inglis SC, Clark RA, McAlister FA, et al. Which components of heart failure programmes are effective? A systematic review and meta-analysis of the outcomes of structured telephone support or telemonitoring as the primary component of chronic heart failure management in 8323 patients: abridged cochrane review. Eur $\mathrm{J}$ Heart Fail 2011;13:1028-40.

6 Hernandez C, Jansa M, Vidal M, et al. The burden of chronic disorders on hospital admissions prompts the need for new modalities of care: a cross-sectional analysis in a tertiary hospital. QJM 2009;102:193-202.

7 Australian Institute of Health and Welfare. Potentially preventable hospitalizations in Australia by small geographic areas, 2019. Available: https://www.aihw.gov.au/reports/primary-health-care/ potentially-preventable-hospitalisations/contents/overview

8 Landolina M, Perego GB, Lunati M, et al. Remote monitoring reduces healthcare use and improves quality of care in heart failure patients with implantable defibrillators: the evolution of management strategies of heart failure patients with implantable defibrillators (EVOLVO) study. Circulation 2012;125:2985-92.

9 Seto E. Cost comparison between telemonitoring and usual care of heart failure: a systematic review. Telemed J E Health 2008;14:679-86.

10 Bashi N, Karunanithi M, Fatehi F, et al. Remote monitoring of patients with heart failure: an overview of systematic reviews. J Med Internet Res 2017;19:e18.

11 Conway A, Inglis SC, Chang AM, et al. Not all systematic reviews are systematic: a meta-review of the quality of systematic reviews for non-invasive remote monitoring in heart failure. J Telemed Telecare 2013;19:326-37.

12 Purcell R, Mclnnes S, Halcomb EJ. Telemonitoring can assist in managing cardiovascular disease in primary care: a systematic review of systematic reviews. BMC Fam Pract 2014;15:43.

13 Hong Y, Lee SH. Effectiveness of tele-monitoring by patient severity and intervention type in chronic obstructive pulmonary disease patients: a systematic review and meta-analysis. Int J Nurs Stud 2019;92:1-15.

14 Kruse C, Pesek B, Anderson M, et al. Telemonitoring to manage chronic obstructive pulmonary disease: systematic literature review. JMIR Med Inform 2019;7:e11496.

15 Bolton CE, Waters CS, Peirce S, et al. Insufficient evidence of benefit: a systematic review of home telemonitoring for COPD. J Eval Clin Pract 2011;17:1216-22.

16 Farias FACde, Dagostini CM, Bicca YdeA, et al. Remote patient monitoring: a systematic review. Telemed J E Health 2020;26:576-83.

17 PROSPERO International prospective register of systematic reviews. The impact of remote patient monitoring on acute hospital use. 2020. National Institute for health research. Available: https:// www.crd.york.ac.uk/prospero/display_record.php?RecordID= 142523

18 Joanna Briggs Institute. Critical appraisal tools. 2020. University of Adelaide. Available: https://joannabriggs.org/ebp/critical_appraisal_ tools

19 The National Institute for Health and Care Excellence (NICE) and the Scottish Intercollegiate Guidelines Network (SIGN). Algorithm for classifying study design for questions of effectiveness. Available: https://www.sign.ac.uk/assets/study_design.pdf [Accessed $22 \mathrm{Apr}$ 2020].

20 PRISMA. Preferred reporting items for systematic reviews and metaanalyses 2015. Available: http://www.prisma-statement.org/

21 Hale TM, Jethwani K, Kandola MS, et al. A remote medication monitoring system for chronic heart failure patients to reduce readmissions: a Two-Arm randomized pilot study. J Med Internet Res 2016;18:e91.

22 Piccini JP, Mittal S, Snell J, et al. Impact of remote monitoring on clinical events and associated health care utilization: a nationwide assessment. Heart Rhythm 2016;13:2279-86.

23 Mehran R, Vogel B, Ortega R, et al. The Lancet Commission on women and cardiovascular disease: time for a shift in women's health. Lancet 2019;393:967-8.

24 The Lancet. Cardiology's problem women. Lancet 2019;393:959.

25 Amara W, Montagnier C, Cheggour S, et al. Early detection and treatment of atrial arrhythmias alleviates the arrhythmic burden in paced patients: the SETAM study. Pacing Clin Electrophysiol 2017;40:527-36.

26 Bulava A, Ošmera O, Šnorek M, et al. Cost analysis of telemedicine monitoring of patients with implantable cardioverter-defibrillators in the Czech Republic. Cor Vasa 2016;58:e293-302.

27 Geller JC, Lewalter T, Bruun NE, et al. Implant-based multi-parameter telemonitoring of patients with heart failure and a defibrillator with vs. without cardiac resynchronization therapy option: a subanalysis of the IN-TIME trial. Clin Res Cardiol 2019;108:1117-27. 
28 Hansen C, Loges C, Seidl K, et al. Investigation on routine followup in congestive heart failure patients with remotely monitored implanted cardioverter defibrillators systems (InContact). BMC Cardiovasc Disord 2018;18:131.

29 Heidbuchel H, Hindricks G, Broadhurst P, et al. EuroEco (European health economic trial on home monitoring in ICD patients): a provider perspective in five European countries on costs and net financial impact of follow-up with or without remote monitoring. Eur Heart $J$ 2015;36:158-69.

30 Lüthje L, Vollmann D, Seegers J, et al. A randomized study of remote monitoring and fluid monitoring for the management of patients with implanted cardiac arrhythmia devices. Europace 2015;17:1276-81.

31 Tajstra M, Sokal A, Gadula-Gacek E, et al. Remote supervision to decrease hospitalization rate (result) study in patients with implanted cardioverter-defibrillator. Europace 2020;22:769-76.

32 Zakeri R, Morgan JM, Phillips P, et al. Impact of remote monitoring on clinical outcomes for patients with heart failure and atrial fibrillation: results from the REM-HF trial. Eur J Heart Fail 2020;22:543-53.

33 Böhm M, Drexler H, Oswald H, et al. Fluid status telemedicine alerts for heart failure: a randomized controlled trial. Eur Heart $J$ 2016;37:3154-63.

34 Boriani G, Da Costa A, Quesada A, et al. Effects of remote monitoring on clinical outcomes and use of healthcare resources in heart failure patients with biventricular defibrillators: results of the MORE-CARE multicentre randomized controlled trial. Eur J Heart Fail 2017;19:416-25.

35 Sardu C, Santamaria M, Rizzo MR, et al. Telemonitoring in heart failure patients treated by cardiac resynchronisation therapy with defibrillator (CRT-D): the TELECART study. Int $J$ Clin Pract 2016;70:569-76.

36 Akar JG, Bao H, Jones PW, et al. Use of remote monitoring is associated with lower risk of adverse outcomes among patients with implanted cardiac defibrillators. Circ Arrhythm Electrophysiol 2015;8:1173-80.

37 Ladapo JA, Turakhia MP, Ryan MP, et al. Health care utilization and expenditures associated with remote monitoring in patients with implantable cardiac devices. Am J Cardiol 2016;117:1455-62.

38 Koehler F, Koehler K, Deckwart O, et al. Efficacy of telemedical interventional management in patients with heart failure (TIM-HF2): a randomised, controlled, parallel-group, unmasked trial. Lancet 2018;392:1047-57.

39 Kalter-Leibovici O, Freimark D, Freedman LS, et al. Disease management in the treatment of patients with chronic heart failure who have universal access to health care: a randomized controlled trial. BMC Med 2017;15:90.

40 Ong MK, Romano PS, Edgington S, et al. Effectiveness of remote patient monitoring after discharge of hospitalized patients with heart failure: the better effectiveness after transition -- heart failure (BEATHF) randomized clinical trial. JAMA Intern Med 2016;176:310-8.

41 Chatwin M, Hawkins G, Panicchia L, et al. Randomised crossover trial of telemonitoring in chronic respiratory patients (TeleCRAFT trial). Thorax 2016;71:305-11.
42 Witt Udsen F, Lilholt PH, Hejlesen O, et al. Cost-effectiveness of telehealthcare to patients with chronic obstructive pulmonary disease: results from the Danish 'TeleCare North' cluster-randomised trial. BMJ Open 2017;7:e014616.

43 Sink E, Patel K, Groenendyk J, et al. Effectiveness of a novel, automated telephone intervention on time to hospitalisation in patients with COPD: a randomised controlled trial. J Telemed Telecare 2020;26:132-9.

44 Achelrod D, Schreyögg J, Stargardt T. Health-economic evaluation of home telemonitoring for COPD in Germany: evidence from a large population-based cohort. Eur J Health Econ 2017;18:869-82.

45 Bingler M, Erickson LA, Reid KJ, et al. Interstage outcomes in infants with single ventricle heart disease comparing home monitoring technology to three-ring binder documentation: a randomized crossover study. World J Pediatr Congenit Heart Surg 2018;9:305-14.

46 Celler B, Varnfield M, Jayasena R. What have we learned from the CSIRO national NBN telehealth trial? Stud Health Technol Inform 2018;246:2461-17

47 De Luca R, Bramanti A, De Cola MC, et al. Tele-health-care in the elderly living in nursing home: the first Sicilian multimodal approach. Aging Clin Exp Res 2016;28:753-9.

48 Flaherty LR, Daniels K, Luther J, et al. Reduction of medical hospitalizations in veterans with schizophrenia using home telehealth. Psychiatry Res 2017;255:153-5

49 Trucco F, Pedemonte M, Racca F, et al. Tele-monitoring in paediatric and young home-ventilated neuromuscular patients: a multicentre case-control trial. J Telemed Telecare 2019;25:414-24.

50 D'Ancona G, Safak E, Senges J, et al. Activation of remote monitoring for cardiac implantable electronic devices: small dog for tall weeds. Clin Res Cardiol 2017;106:833-9.

51 Schreier G, Eckmann H, Hayn D, et al. Web versus APP: compliance of patients in a telehealth diabetes management programme using two different technologies. J Telemed Telecare 2012;18:476-80.

52 Bohingamu Mudiyanselage S, Stevens J, Watts JJ, et al. Personalised telehealth intervention for chronic disease management: a pilot randomised controlled trial. J Telemed Telecare 2019;25:343-52.

53 Agboola S, Jethwani K, Khateeb K, et al. Heart failure remote monitoring: evidence from the retrospective evaluation of a realworld remote monitoring program. J Med Internet Res 2015;17:e101.

54 Klersy C, De Silvestri A, Gabutti G, et al. Economic impact of remote patient monitoring: an integrated economic model derived from a meta-analysis of randomized controlled trials in heart failure. Eur $J$ Heart Fail 2011:13:450-9.

55 Nancarrow S, Banbury A, Buckley J. Evaluation of a national broadband Network-enabled telehealth trial for older people with chronic disease. Aust Health Rev 2016;40:641-8.

56 Peretz D, Arnaert A, Ponzoni NN. Determining the cost of implementing and operating a remote patient monitoring programme for the elderly with chronic conditions: a systematic review of economic evaluations. J Telemed Telecare 2018;24:13-21. 